\title{
Aproximaciones a Octavio Paz *
}

Con este libro del profesor Angel Flores, son ya tres los homenajes dedicados, en los Estados Unidos, a la obra de este "mexicano universal", como ha dado en llamarle, junto con muchos- otros, Ivar Ivask.

El primero de los homenajes lo organizó el profesor Alfredo A. Roggiano, director de publicaciones del Instituto Internacional de Literatura Iberoamericana, quien dedicó por completo el No. 74 (enero-marzo de 1971) de la Revista Iberoamericana a la obra de Octavio Paz. Entre los muchos méritos de esta Revista debemos anotar la inclusión de la bibliografía más completa de y sobre Octavio Paz publicada hasta la fecha y compilada por el profesor Alfredo A. Roggiano, director de la misma. Bibliografía que también aparece en el libro de ensayos sobre Paz intitulado: The Perpetual Present: The Poetry and Prose of Octavio Paz, editado por Ivar Ivask y publicado por la University of Oklahoma Press en 1973. Casi todos los artículos incluidos en este libro aparecieron originalmente en el volumen 46, No. 4 de Books Abroad (otoño de 1972) cuyo editor es el mismo Ivask. La mayoría de estos artículos fueron, a su vez, leidos durante el simposio dedicado a Paz por la Universidad de Oklahoma en 1972.

En el número 31 de Plural (abril de 1974, p. 77), Manuel Durán escribe a propósito de The Perpetual Present que "no hay nada publicado en español que pueda compararse en variedad y riqueza, a este libro, para un acercamiento a la obra de Paz." En el No. 36, página 100 de la misma revista el profesor Durán ha rectificado este juicio, reconociendo la primacía e importancia del simposio organizado por el profesor Roggiano. Si tomamos en consideración, sin embargo, que el libro del profesor Flores fue publicado en enero (o sea tres meses antes de la aparición del comentario del Dr. Durán en Plural) su juicio nos sigue pareciendo injusto ya que varios críticos colaboraron en las tres publicaciones antes mencionadas, y en el volumen de Flores se reproduce parte de lo publicado en la Revista Iberoamericana. Me parece que el resultado de cada uno de estos homenajes debería evaluarse lo más equitativa y desapasionadamente posible, y, si de eso se trata, cabría mencionar un error que aparece en el bosquejo bibliográfico incluido en The Perpetual Present (p. 132), en donde el libro de Ramón Xirau: Octavio Paz o el sentido de la palabra aparece como el primer libro escrito sobre Octavio Paz. E1 libro de Claire Céa, publicado en la edición de Seghers "Poètes d'aujourd'hui", data de 1965 y contiene, como es sabido, además del texto crítico de la autora, interesantes fotografías y una selección de traducciones al francés debidas a Jean-Clarence Lambert, Lina Leclercq y C. Céa de poemas que aparecerán más adelante en Ladera este ("Madurai", "Utacamud", "El balcón", etc.).

*Aproximaciones a Octavio Paz (Mexico: Joaquin Mortiz, 1971). 
En Aproximaciones a Octavio $\mathrm{Paz}$, los artículos, reseñas y comentarios están ordenados de acuerdo con el tema central del poema o libro de poemas del que se ocupan. Una breve nota biográfica tomada de La centena precede al prólogo de Julio Cortázar. Nota que nos parece algo incompleta ya que no incluye mención alguna de la febril actividad profesional en la que Paz se ha visto envuelto de 1968 hasta la fecha.

El prólogo de Cortazar constituye una lúcida síntesis de la obra de Paz. Éscrito en ese medio tono poético que pulsa con afecto y que es tan característico del autor de Rayuela, establece, por medio de su título un símil entre la poesía de Paz y la estrella de mar. En "Homenaje a una estrella de mar", Cortázar explica el deslumbramiento que experimenta ante ambas: "Hablo de maravillarse, porque frente a esa coagulación de lo múltiple en unidad, la mirada presiente ya el nuevo punto de partida que insinúa esa humeda brújula en la que cada punta marca rumbos jamás balizados en nuestras,cartas de viaje."

“La poesía de Octavio Paz", por Juan García Ponce, es también una visión de conjunto de la obra de Paz, a través de la cual el autor trata de mostrar la unidad orgánica de ésta. Unidad que trasciende todo esfuerzo por ordenar cronológicamente los escritos de Paz. García Ponce estudia los temas principales de la obra de Paz: la caída, el amor, la reconciliación de los contrarios, la búsqueda del origen, la soledad, la participación que culmina en comunión y la conciencia de la historia y del tiempo:

Conciencia que vive la historia como parte de ella misma, conciencia que sufre el tiempo afirmando su temporalidad, conciencia que se busca en el pasado y lo remonta para afirmarse en el presente, la obra de Octavio Paz invita a la participación desde la soledad sin proponernos hermosas soluciones apócrifas, dándonos la vida como lo que es: interrogación y búsqueda, una aventura total.

Ramón Xirau contribuye con tres artículos breves al simposio que nos ocupa. El primero: "Del símbolo a la imagen" es brillante, prometedor. . .en otras palabras, demasiado corto. En él, Xirau desarrolla una tesis, según la cual el símbolo sería un "resumen y culminación de los demás estratos imaginativos" (imágenes, metáforas, paradojas). De acuerdo con Xirau, los símbolos que utiliza Paz no contienen, como los de Joyce por ejemplo, una multiplicidad de niveles, sino que se acercan a la imagen: "hasta darnos la sensación de que el nuevo mundo introducido por el poeta es un mundo imitado, correlato poético de la realidad." Su segundo artículo: "Himno entre ruinas: La palabra, fuente de toda liberacion," constituye un fino e inteligente análisis del primer poema extenso de Paz, interpretado desde la perspectiva de la dialéctica soledad-comunión a la que Xirau ha dedicado ya varios estudios que incluyen a otros poetas mexicanos como. Villaurrutia y Gorostiza. La correlación entre el tema de la soledad y las imágenes sólidas, pétreas, así como la traducción de la comunión en imágenes instantáneas en donde la presencia es un estallido autodestructivo están muy bien apuntadas. A propósitg̨ del verbo liberador Xirau escribe: "El hombre es palabra y la palabra es fundamento de todo lo creado. 
El hombre 'arbol de imágenes', encuentra en la palabra su liberación." Su tercera contribución a este volumen es un breve análisis del poema "Salamandra". Según Xirau, la salamandra simboliza a Axólotl, "el dos seres" y a Xólotl, "perro guía del infierno", "hacedor de hombres" y "penitente". En una nota al pie de la página encontramos una pregunta interesante que contribuye a multiplicar los niveles simbólicos de la salamandra: "¿ No existirá una relación más o menos deseada entre la 'salamandra' del poema y la piedra preciosa que con el nombre de 'salamandra' adoran los vishnuitas? Piedra espiral como la cola de la salamandra, contiene a Vishnú. ¿ No es la 'salamandra' lo que se conserva--Vishnú conservador del mundo-a pesar de todas las mutaciones aparentes?"

Carlos Fuentes, en su artículo "El tiempo", ve en la obra de Paz un anhelo, o aún más, un angustioso esfuerzo por captar el relámpago instantáneo durante el cual cobra cuerpo la palabra poética. Nos dice que los escritos de Paz son una "constante encarnación del tiempo", de los tres tiempos unidos en la perpetua sincronía del poema. Este estudio, sin embargo, parece un tanto general cuando se lo compara al escrito por I ulio Requena e intitulado: "Poética del tiempo." Aún cuando el estilo del articulo de Fequena tiende a ser algo intrincado debido a la sobreabundancia de términos esotéricos y de cultismos ("proceso desbastador y fungible del cosmos", "arcano heterocósmico del espejo", "terrribilidad espiritual", "palingenesias del tiempo", etc.,) el fondo del mismo no sólo es serio sino también utilísimo para la comprensión de la obra de Paz. El autor analiza el trasfondo pre-socrático, azteca, cristiano, brahamán, budista, tántrico y surrealista de la poesía de Paz, da pertinentes ejemplos y amplía sus conclusiones por medio de largas notas al pie de página. Resultan particularmente interesantes los párrafos dedicados al análisis del instante en la obra de Paz, del presente puro, sincrónico:

Por otra parte, ¿ no constituye esta épica del instante la primera representación contemporánea, orgánica y preocupada - dentro de la poesía hispanoamericana - acerca de la idea de un tiempo tetradimensional? Repárese en la obsesión y desasosiego del poeta por penetrar el misterio de un universo de cuatro dimensiones, donde según los físicos - el pasado existe aún y el porvenir existe ya.

Jean Franco, en "El espacio" (aparecido antes en la Revista Iberoamericana, No. 74) analiza, en una excelente exposición, la importancia de la noción de espacio en la poésia de Paz. Espacios tipográficos y rítmicos que se equiparan a los silencios musicales, concentrándose en el significado del espacio en Blanco y concluyendo que éste: "Es un poema que no permite la trascendencia, que nos centra en el presente." Manuel Durán cortribuye con un artículo muy conocido, ya que fue publicado por vez primera en 1962 y traducido al inglés en 1963. "Libertad y erotismo" sigue, sin embargo, teniendo vigencia a pesar de que en él no aborda aún el Dr. Durán el estudio de los elementos orientales en la poesía de Paz (como lo hará más tarde en: "La huella del.Oriente en la poesía de O. Paz" (Revista Iberoamericana, No. 74.)). La mayor contribución de este artículo a la comprensión de la obra de Paz ha sido quizás la de apuntar la importancia del tacto en la misma: "el tacto parece tener 
para Paz la misma importancia que el olfato para Baudelaire."

Luis Alfonso Díez en "Poesía y pensamiento poético" presenta un cotejo parcial de la poética y de la poesía de Paz. Empieza por analizar lo que la creación de la palabra significa para Paz así como la importancia de los dilemas espacio-tiempo, vértigo-fijeza, soledad-comunión, identidad-otredad, y concluye diciendo que Paz ve a la literatura como pasión: "Si hay algo que de verdad pueda servirnos de común demoninador a toda su obra es la pasión. Ese 'arte como pasíon universal', que dijera en varias partes de sus escritos." En "Historia singular de un poema de Octavio Paz", Luis Mario Schneider coteja las dos versiones de un poema de juventud de Paz (la versión definitiva de "Nocturno" está incluida en Libertad bajo palabra); e interpreta las variantes de ambas versiones, mientras que Eduardo González Lanuza nos ofrece una reseña de $A$ la orilla del mundo (publicado en Sur, No. 109, noviembre de 1943, pp. 70-74) desde la perspectiva de lo que él llama el romanticismo (en el sentido de "Sturm und Drang") de Octavio Paz. El breve análisis de "La rama", escrito por Luis Leal podría servir como modelo de explicación de texto. El estudio de algunos de los símbolos fundamentales de la poesía de Paz: agua, luz, río, piedra, espejo, sangre, ojo, árbol, sueño, es el tema de uno de los artículos más substanciales del libro que nos ocupa: "El símbolo en $L a$ estación violenta de Octavio Paz" por Carlos H. Magis, quien analiza el valor primario de cada uno de estos símbolos, relacionándolos y contrastándolos entre sí, además de mencionar algunos de sus equivalentes. El autor concluye, como la mayoría de los críticos de Paz, que la simbología utilizada por éste último posee una gran unidad orgánica. Para el Dr. Magis, el lenguaje de Paz es:

orgánico en cuanto que este lenguaje simbólico, metasemántico, funciona como una trama dentro de la cual los diversos signos y sus equivalentes cobran su plena significación, desarrollando su máxima riqueza y dan pruebas de su grande potencia connotativa.

El análisis de "Himno entre ruinas", por John M. Fein es también muy acertado. Su autor muestra con agudeza y claridad la alternancia de las dos voces del poeta, la paradisíaca y la amarga, concluyendo que: "La última estrofa no es solamente la resolución sintética del poema, sino también uno de los pocos momentos de franco éxtasis en la poesía de Paz. Por la manera personal de fundir el alto concepto del destino humano con la elegancia verbal, es para este comentador una de las estrofas más bellas de la poesía de habla española del siglo XX." La breve reseña de Piedra de sol por Tomás Segovia, publicada originalmente en 1965, podría verse como un brillante prólogo al mejor estudio publicado hasta la fecha sobre este poema: "Descripción de Piedra de sol" de José Emilio Pacheco que apareciera por vez primera en el ya mencionado número de la Revista Iberoamericana dedicado a Paz. Los apuntes de E. Caracciolo Trejo sobre "Ustica" también contribuyen a este esfuerzo común por desentrañar los varios niveles de significación que encierran los poemas de Octavio Paz. 
Roberta Seabrook se destaca, una vez más, como una de las especialistas más serias e inteligentes de la obra de Paz. Su estudio de "Vrindaban" atestigua del esfuerzo que su autora sigue haciendo por ayudarnos a comprender mejor las influencias orientales en la poesía de Paz, del último Paz sobre todo. Su análisis del plurisimbolismo del pavo-real nos pareció particularmente acertado e interesante así como la reivindicación del orientalismo de términos como "saltimbanqui" y "mono del absoluto" en los que Manuel Durán lee una degradación del santón oriental. Muy comendable es el artículo de Julio Ortega: "Viento entero: El tiempo en un día", escribe: "El poema dialoga con sí mismo: reitera imágenes, las corrige, las amplía. La recurrencia erótica es su mecanismo: el acto creador se autocontempla en su rigor como en su apertura ; el amor conjuga las contradicciones al transparentar la realidad: las evidencias en tanto instante que relieva el contorno." Mientras que Julio Ortega estudia el poema desde su perspectiva oriental, Octavio Armand lo analiza situándolo dentro de la perspectiva de la poesía occidental de este siglo (modernismo y "modernism", Darío, Othón, Machado, Elliot, Pound), y universal, demostrando cómo el rito tántrico y el prehispánico se dan la mano en este bellísimo poema. Javier Sologuren contribuye con dos sensitivos, aun cuando someros, comentarios sobre "Eje" y "Cuento de dos jardines".

Los dos artículos que se ocupan de Blanco son excelentes. El de Guillermo Sucre fue publicado originalmente como reseña del libro-poema de Paz en 1968 y continúa siendo una de las mejores interpretaciones del mismo. En: "Blanco: un archipiélago de signos", el poeta, crítico y profesor venezolano, ve en Blanco un producto de la conciencia crítica contemporánea, un nuevo comienzo frente al fracaso en el que desemboca todo intento de interpretación del mundo por medio del arte. Contiene una descripción física del poema y de sus dimensiones: "mundo, mujer, poema" y quizás su mayor contribución al mejor entendimiento de este poema sea el de la diferencia que apunta entre Blanco y Un coup de dés. Si el poema de Mallarmé: "Concluye con el reconocimiento de la invulnerabilidad del azar" lo que constituye precisamente al punto de partida de Paz: "el poema se condensa en el acto que lo propicia. Pero el acto de escribirlo no vale sino por el acto de leerlo: llamado al lector para que haga decir al poema. De ahí el título: es un texto en blanco (como el mundo), está y no está escrito, en él la palabra está y no está dicha. De esta manera el lector tiene, al leerlo, que asumirlo igualmente, convertirlo en experiencia personal. Leer, también, no es descubrir un sentido, sino, sobre todo, hacerlo posible." El segundo análisis de Blanco se lo debemos a Enrique Pezzoni (quien también contribuye con un artículo sobre los Discos visuales) y se intitula: "Blanco: la respuesta al deseo" (tomado de la Revista Iberoamericana, No. 78). El autor parte de una cita de Paz sobre el surrealismo: "Conocer es un acto que transforma aquello que se conoce" y podría calificarse de análisis linguíístico-literario. Apunta el carácter experimental de toda gran poesía asi como la importancia del significante como realidad única en la poesía contemporánea. Va hasta utilizar el término "programada" al referirse a la escritura del poema. De acuerdo con Pezzoni, la meta de Paz es el deseo de encarnación de la palabra dentro del texto mismo y en 
relación a los otros significantes: "Blanco no anuncia el acto poético: es el acto, la imagen ya encarnada, la posibilidad cumplida de proyectar lo sucesivo en lo simultáneo." Es el "pacto definitivo entre el signo cuerpo y el signo no-cuerpo a que ha logrado llegar la filosofía budista." El mismo crítico se ocupa, como ya dijimos, de comentar los Discos visuales, mostrando cómo Topoemas formaron el puente entre la poesía unidimensional y la poesía espacial de Paz. Nos parece sin embargo que una descripción del mecanismo del YChing es indispensable para lograr desentrañar el plurisimbolismo contenido en los Discos.

El estudio lingüístico de Topoemas, por Saúl Yurkievich es excelente y confirma nuestra opinión de lo necesarios y útiles que son los conocimientos no sólo literarios y filosóficos sino linguiísticos para comprender en profundidad la obra de $\mathrm{Paz}$.

Aplaudimos el esfuerzo del profesor Flores por reunir en Aproximaciones a Octavio Paz los puntos de vista críticos de varios especialistas de la poesía Latinoamericana contemporánea, así como la inclusión de artículos ya publicados pero difíciles de conseguir como son los de Tomás Segovia y Guillermo Sucre. 